\title{
Preschool Completion
}

National Cancer Institute

\section{Source}

National Cancer Institute. Preschool Completion. NCI Thesaurus. Code C70433.

Indicates that preschool is the highest level of education achievement. 